\title{
A META-ANALYSIS OF ABNORMAL GLUCOSE METABOLISM IN FIRST-EPISODE DRUG-NAIVE SCHIZOPHRENIA
}

\author{
Wenjuan Yang, Lulu Zheng, Bei Zheng, Shen Zeng, Jingjing Li, Bingqing Liang, \\ Jun Zhu \& Meiling Zhang \\ Department of Pharmacy, TongDe Hospital of Zhejiang Province, Hangzhou, Zhejiang, China
}

received: 1.4.2019;

revised: 10.3.2020;

accepted: 26.3 .2020

\section{SUMMARY}

Background: Patients with schizophrenia exhibit a higher mortality rate compared with the general population. This mortality has been attributed predominantly by the high risk of type 2 diabetes mellitus in the patients. We aimed to assess the inherent risk of glucose metabolism abnormalities in first-episode drug-naïve schizophrenia.

Subjects and methods: We searched English database (PubMed, EMBASE, MEDLINE, Cochrane Library databases) and Chinese database (Wan Fang Data, CBM disc, VIP, and CNKI) from their inception until Jul 2018 for case-control studies examining glucose metabolism abnormalities. Measurements, such as fasting plasma glucose levels, fasting plasma insulin levels, insulin resistance and HbAlc levels in first-episode antipsychotic-naive patients were used to test for prediabetes. Standardized/weighted mean differences and $95 \%$ confidence intervals were calculated and analyzed.

Results: 19 studies (13 in English and 6 in Chinese) consisting of 1065 patients and 873 controls were included. Fasting plasma glucose levels (95\% CI; 0.02 to 0.29; P=0.03), 2 h plasma glucose levels after an OGTT (95\% CI; 0.63 to 1.2; P<0.00001), fasting plasma insulin levels (95\% CI; 0.33 to $0.73 ; P<0.00001)$, insulin resistance (95\% CI; 0.29 to $0.6 ; P<0.00001)$ in patients with firstepisode schizophrenia were significant elevated. There was no significant difference in HbAlc level (95\% CI; -0.34 to 0.18 ; P=0.54) in patients with first-episode schizophrenia compared with controls.

Conclusions: This meta-analysis showed that glucose metabolism was impaired in patients with first-episode schizophrenia. Higher quality studies with larger samples are warranted to confirm these findings.

Key words: First-episode schizophrenia - drug-nä̈ve - glucose metabolism

$$
* * * * *
$$

\section{INTRODUCTION}

It is now widely acknowledged that schizophrenia characterized by emotional, cognitive, and behavioral dysfunctions, which is a severe neurodevelopmental disorder. About $1 \%$ of the population worldwide suffering from schizophrenia (Zheng et al. 2018). Study demonstrate that schizophrenia contributes 13.4 million years of life lived with disability (YLDs) to burden of disease globally, equivalent to $1.7 \%$ of total YLDs globally in 2016 (Charlson et al. 2018). Furthermore, schizophrenia is the most costly mental disorders of all mental illnesses, for instance, societal economic burden of schizophrenia in US was $\$ 62.7$ billion in 2002 . Recently, prevalence-based approach estimated that the costs amounted to $\$ 155.7$ billion in 2013 (Cloutier et al. 2016, Wu et al. 2005).

Schizophrenia is associated with elevated suicide rates and premature death. Numerous studies have identified that patient with schizophrenia have two-fold to three-fold higher mortality rates compared with general population (Brown et al. 2010, Chesney et al. 2014, Reininghaus et al. 2015). This mortality gap which translates to a life expectancy is around 15 to 21 years shorter in patients with schizophrenia (Hjorthøj et al. 2017). The leading cause of premature death was not only somatic diseases but also cardiovascular diseases (CVD). Moreover, several recent lines of evidence demonstrate that morbidity of CVD was increased among patients with schizophrenia (Capasso et al. 2008, Laursen 2011, Saha et al. 2007). As a major risk factor for CVD, type 2 diabetes mellitus (T2DM) confers an approximately twofold excess risk (Vancampfort et al. 2016). Recent studies demonstrated that diabetes was the most commonly diagnosed specific chronic disease among patients with schizophrenia. They also showed that women with schizophrenia have higher risk than man (Crump et al. 2013). Numerous studies also revealed that antipsychotics used in clinic may contribute to diabetes (Cohen \& Correll 2009, Henderson et al. 2006), especially olanzapine and clozapine (Cohen \& Correll 2009) (Meyer \& Stahl 2009, Yood et al. 2009). However, the latest epidemiological study revealed that diabetes risk in patients who exposed to first- and second-generation antipsychotic drugs were similar, ranging from 1.94 (olanzapine) and 2.19 (aripiprazole) to 3.25 (clozapine) (Rajkumar et al. 2017). Recent reviews identified that schizophrenia confers an endogenous risk for the development of T2DM. Studies have showed that patient with first-episode schizophrenia exhibit alterations in glucose homeostasis compared with matched control (Greenhalgh et al. 2017, Kucukgoncu et al. 2019, Perry et al. 2016, Pillinger et al. 2017).

However, previous meta-analyses did not include non-English databases. Thus, we performed a systematic review and a meta-analysis to assess glucose homeostasis in individuals with schizophrenia. 


\section{SUBJECTS AND METHODS}

\section{Search strategy}

This meta-analysis was performed according to Preferred Reporting Items for Systematic Reviews and Meta-Analyses (PRISMA) (Moher et al. 2009). The studies in our review were searched from English database (PubMed, EMBASE, MEDLINE, Cochrane Library databases) and Chinese databases (Wan Fang Data, CBM disc, VIP, and CNKI) from their inception until 15 July 2018. The key words included "schizophrenia", "psychotic disorders", "Schizophrenic disorders", "schizophrenia", "psychosis", "psychotic", "schizoaffective" and "diabetes mellitus", "diabetes", "glucose", "insulin resistance", "fasting glucose", "glycated hemoglobin", "insulin", "homeostatic model assessment index", "oral glucose tolerance test", "impaired glucose tolerance", "prediabetes", "type 2", "postprandial 2 hour glucose" and "first episode", "early onset", "at risk", "ultra-high risk", "prodrome" and "drug-naïve", "antipsychotic-naïve", "medication", "drug", "antipsychotic". There no language restrictions in search.

\section{Inclusion and Exclusion Criteria}

Inclusion criteria were (1) patients were diagnosed as schizophrenia according to the DSM-IV; (2) patients were $\geq 16$ years of age; (3) patients were antipsychotic naive or $\leq 2$ weeks of antipsychotic treatment; (3) control group were healthy population; (4) fasting plasma glucose concentration (FG) or two hour values in the oral glucose tolerance test (OGTT) or hemoglobin A1 $(\mathrm{HbAlc})$ or insulin resistance or fasting insulin (FI) were assessed.

Exclusion criteria were (1) patients were not diagnosed as schizophrenia; (2) antipsychotic exposure $>2$ weeks; (3) patients were children or elder or pregnant; (4) absence of measures in control group; (5) the review and conference report; (6) preclinical research; (6) study which unable to provide raw data; (7) only prevalence in study.

\section{Statistical Analysis}

Quality appraisal was done using the Newcastle Ottawa Scale (NOS) for case-control studies. Continuous data were analyzed in our analysis. Standardized mean differences (SMDs) or mean difference (MD) and $95 \% \mathrm{CI}$ between cases and controls were calculated and displayed in forest plots. Heterogeneity across studies was assessed with the $\mathrm{I}^{2}$ statistic. Publication bias was assessed using Egger test. All meta-analyzable data were analyzed with the RevMan (Version 5.3) software. A sensitivity analysis and publication bias was assessed using Stata SE 12.0.

\section{Studies screened from Cochrane Library databases, EMBASE, MEDLINE, Pubmed, and Chinese databases (WanFang, Chinese Biomedical, CNKI, Weipu)}

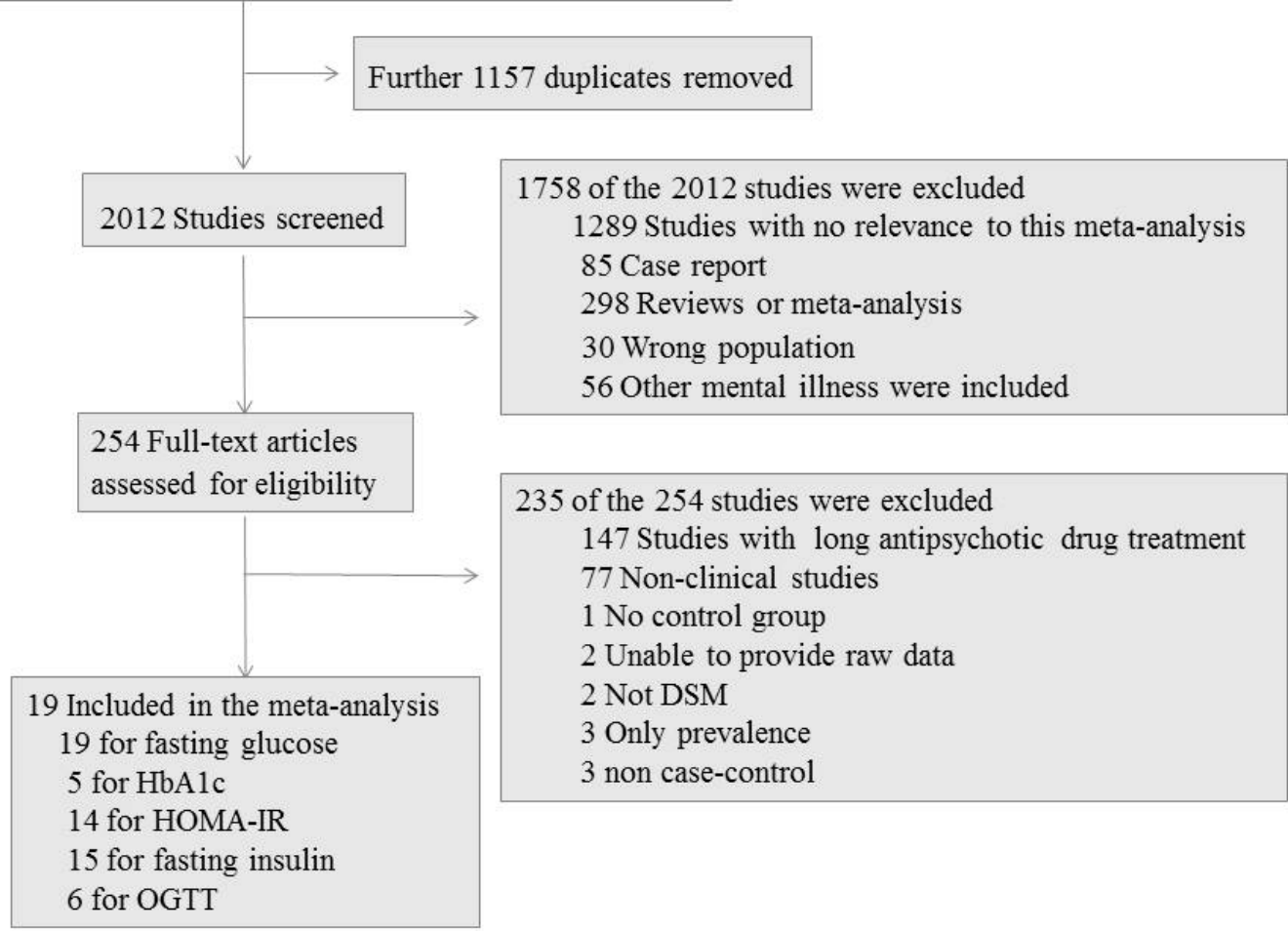

Abbreviations: HbA1c - hemoglobin A1c; HOMA-IR - homeostatic model assessment-insulin resistance; OGTT - oral glucose tolerance test

Figure 1. Study selection for meta-analysis 


\section{RESULT}

\section{Search results and included participants}

We screened 2012 potential, non-duplicate articles. The search process is demonstrated in Figure 1. 19 studies met the inclusion criteria and were included in the quantitative synthesis (Table 1). There were 19 studies with data on FG, 5 for HbA1c, 14 for HOMA-IR, 15 for FI and 6 for two-hour OGTT. Study qualities were rated based on Newcastle-Ottawa Scale (NOS) (Table 2).

\section{Fasting glucose concentration}

19 studies involving 1065 patients and 873 controls were included in our analysis. Pooling this data showed that FG was significantly elevated in patients compared with controls $\left(95 \% \mathrm{CI} ; 0.05\right.$ to $\left.0.41 ; \mathrm{I}^{2}=73 \% ; \mathrm{P}=0.01\right)$. Findings of the Egger test $(\mathrm{P}=0.106)$ suggested that publication bias was not significant. Sensitivity analyses revealed that estimate of one study was stray from the effect size (Quan 2015). After excluding the divergent study, heterogeneity was decreased $(95 \% \mathrm{CI} ; 0.02$ to $0.29 ; \mathrm{I}^{2}=51 \% ; \mathrm{P}=0.03$ ) (Figure 2).

\section{Two-hour glucose concentration after OGTT}

6 studies measured the level of two-hour OGTT. Compared to healthy controls, a significant elevation was observed in two-hour OGTT (95\% CI; 0.63 to 1.2 ; $\mathrm{I}^{2}=0 \% ; \mathrm{P}<0.00001$ ) (Figure 2). In the context of low study numbers, publication bias was not performed.

\section{Fasting plasma level of insulin}

15 studies measured insulin concentration. Pooling the data suggested increased insulin concentration in patients $\left(95 \% \mathrm{CI} ; 0.22\right.$ to $\left.0.7 ; \mathrm{I}^{2}=80 \% ; \mathrm{P}=0.0002\right)$. Findings of the Egger test $(\mathrm{P}=0.583)$ suggested that publication bias was not significant. There was a high level of heterogeneity in this analysis led by one outlier. Removing this study (Arranz 2004) in a sensitivity analysis reduced heterogeneity to $69 \%(95 \% \mathrm{CI} ; 0.33$ to 0.73 ) (Figure 3).

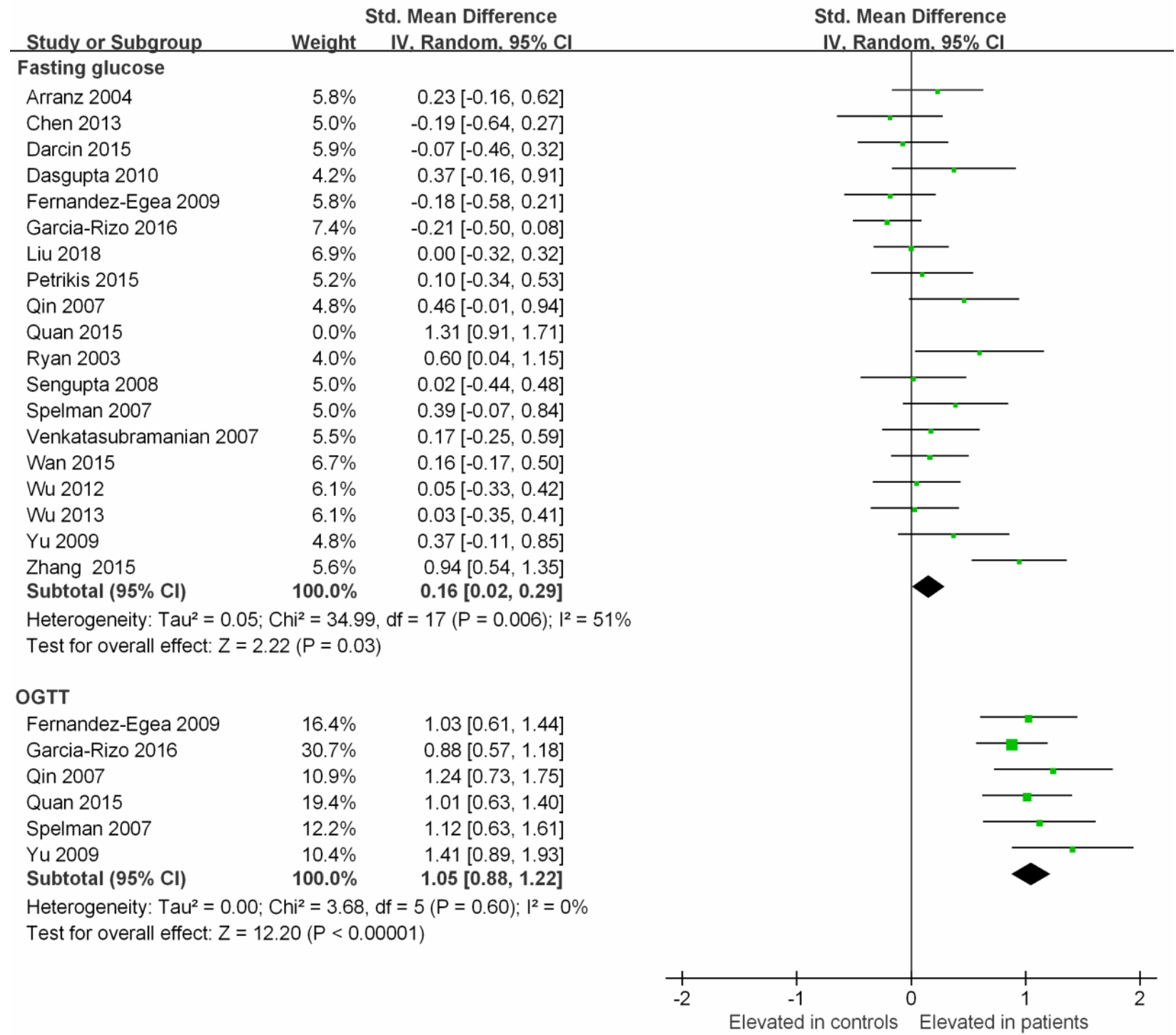

Figure 2. Fasting Glucose Concentrations and 2h OGTT in Patients with First-Episode Schizophrenia and Control 


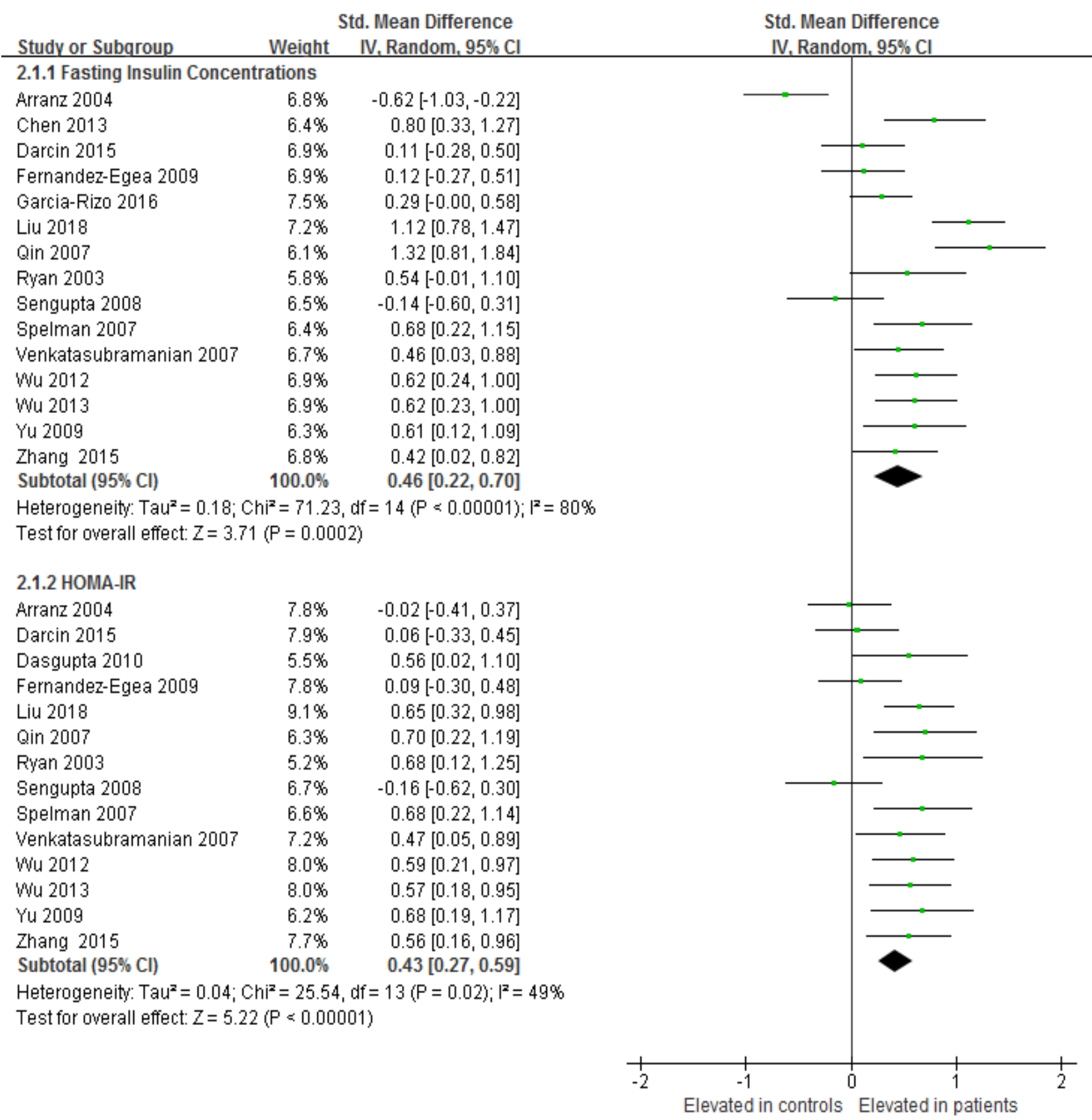

Figure 3. Fasting Insulin Concentrations and HOMA-IR in Patients with First-Episode Schizophrenia and Control

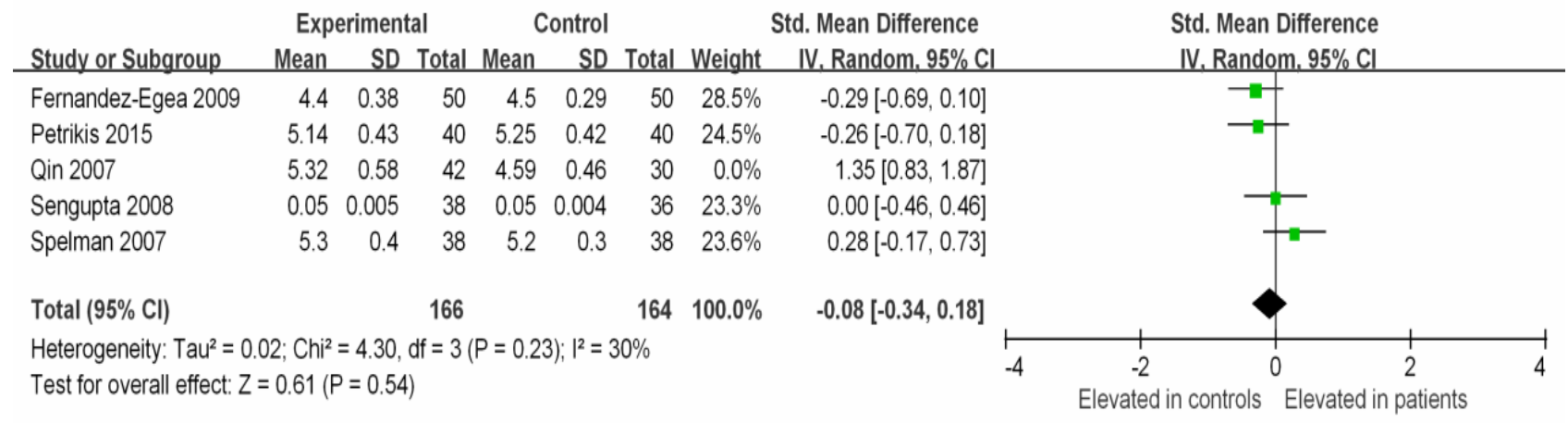

Figure 4. HbAlc level in patients and control 


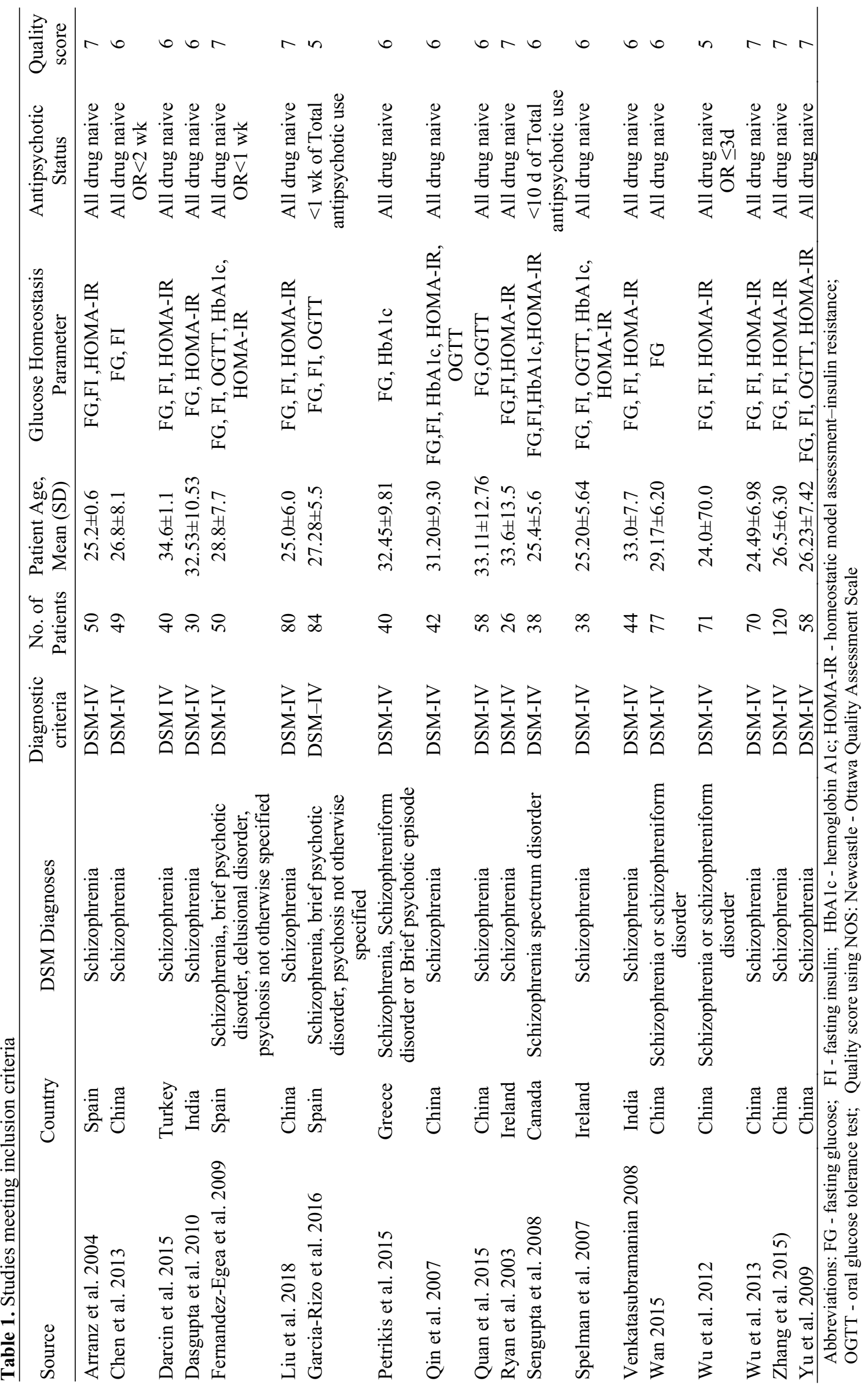




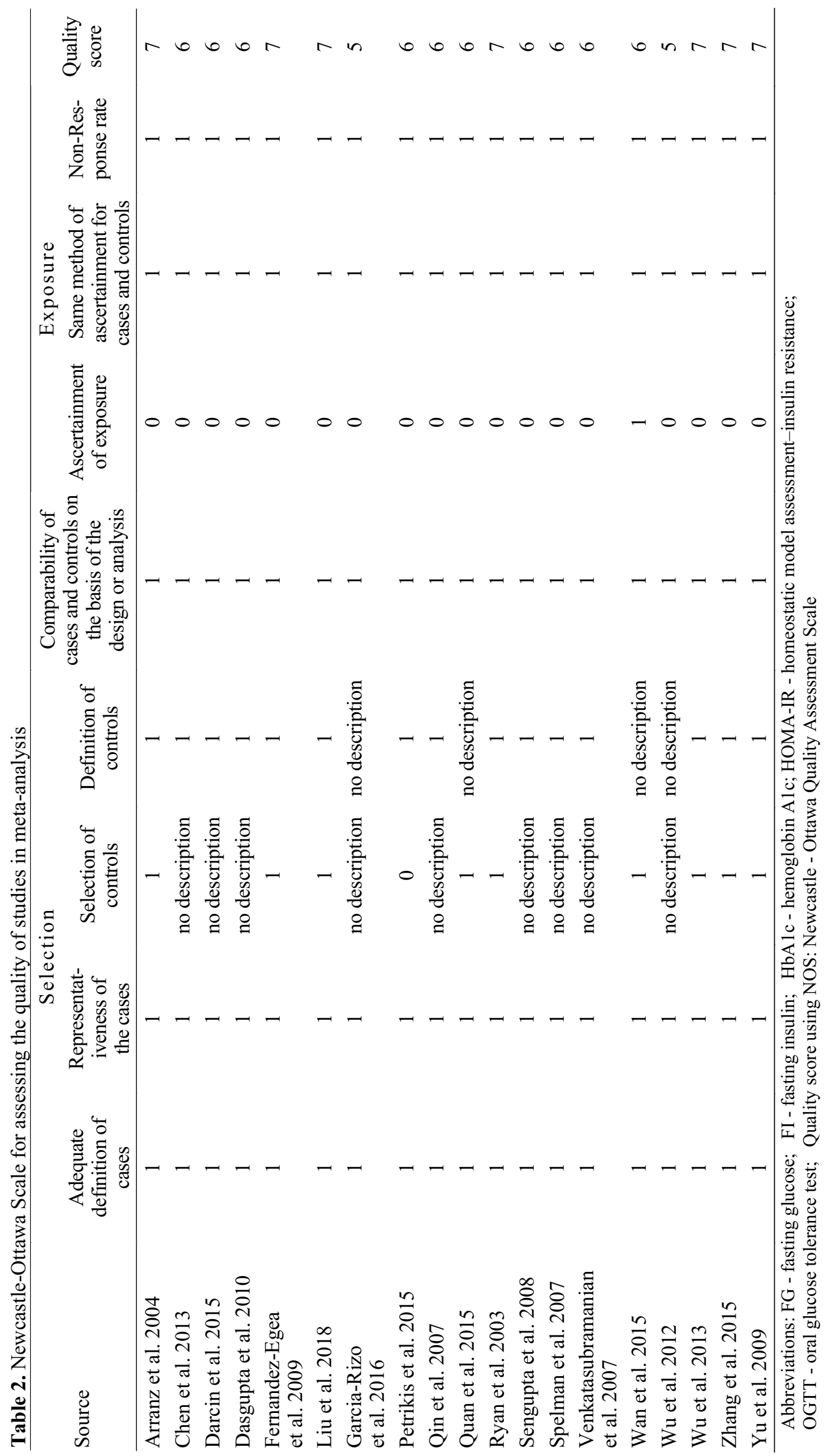




\section{Insulin resistance}

HOMA-IR tool was used in patients and controls to analyze insulin resistance. 14 studies containing 757 patients and 582 controls were included in our analysis. Compared to healthy controls, HOMA-IR in patients was significant increased (95\% CI; 0.29 to $0.6 ; \mathrm{I}^{2}=49 \%$; $\mathrm{P}<0.00001$ ) (Figure 3). Findings of the Egger test $(\mathrm{P}=0.599)$ suggested that publication bias was not significant.

\section{HbA1c level}

5 studies involving 208 patients and 194 controls were used for evaluate HbAlc level. Pooling this data showed that no significant difference in HbAlc level between patients and controls $(95 \% \mathrm{CI} ;-0.34$ to 0.75 ; $\left.\mathrm{I}^{2}=86 \% ; \mathrm{P}=0.47\right)$. Furthermore, sensitivity analysis showed that estimate of one studies were stray from the merger effect amount. After removal of the most divergent study (Qin 2007), heterogeneity was no longer significant $\left(95 \% \mathrm{CI} ;-0.34\right.$ to $\left.0.18 ; \mathrm{I}^{2}=30 \% ; \mathrm{P}=0.54\right)$ (Figure 4). In the context of low study numbers, publication bias was not performed.

There did not appear to be a significant publication bias on funnel plots (Figure 5, 6 and 7).

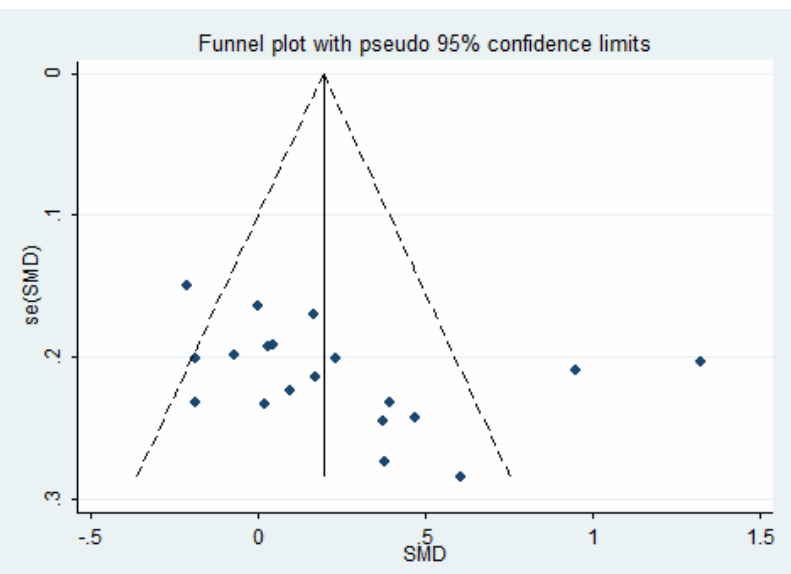

Figure 5. Publication bias of studies about fasting glucose on funnel plots

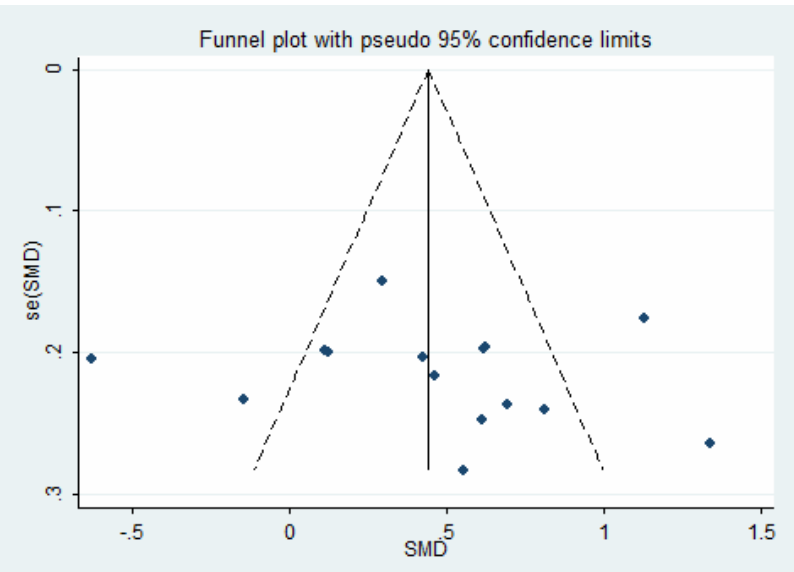

Figure 6. Publication bias of studies about fasting insulin on funnel plots

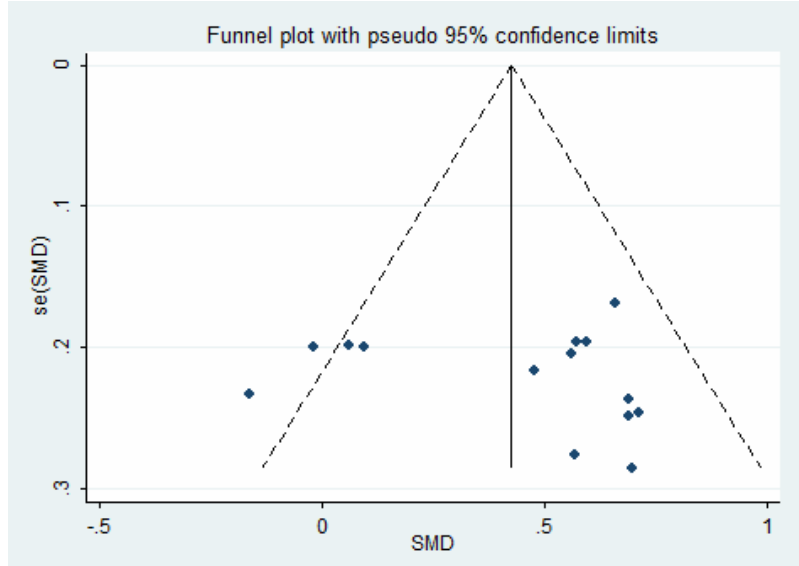

Figure 7. Publication bias of studies about insulin resistance on funnel plots

\section{DISCUSSION}

Our analysis revealed that patients with first-episode schizophrenia did significantly differ from healthy controls in their measurements of FG concentration, two-hour OGTT concentration, insulin concentration and insulin resistance. Compared with healthy controls, drug-naïve patients have higher FG, two-hour OGTT, and insulin levels. Insulin resistance results were also found to be higher. However, HbAlc levels were not significantly changed in patients when compared with controls. These data thus lend support to glycemic abnormality in patients with first-episode psychosis.

Our meta-analysis highlights the inherent risk of patients with first-episode schizophrenia for developing abnormal glucose metabolism. However, the exactly mechanisms of abnormal glucose metabolism in patients with first-episode psychosis are unknown. Studies suggested that inflammation, genetic polymorphisms, and chronic stress can lead to glucose metabolism abnormalities in patients with first episode psychosis (Amare et al. 2017, Belvederi Murri et al. 2016, Kucukgoncu et al. 2019). Recent study showed that familial abnormal glucose metabolism or primary insulin signaling pathway abnormality is related to risk for psychosis (Chouinard et al. 2018). Progression of insulin resistance can lead to metabolic syndrome and T2DM. Moreover, insulin resistance may precede the development of T2DM by 10 to 15 years (Freeman \& Pennings 2018). 8 studies involving Chinese Han in our analysis, our pooled analysis indicated that insulin resistance is more common in patients with first-episode psychosis than in controls.

Several limitations arise from our analysis. Firstly, there was considerable heterogeneity $\left(\mathrm{I}^{2}=81 \%\right)$ in the result of the meta-analysis of fasting plasma glucose concentration. One study (Quan 2015) reported on results of the impaired fasting glucose (IFG). Heterogeneity was decreased from $81 \%$ to $48 \%$ after removing the study in a sensitivity analysis. 8 patients were reported with IFG in this study. IFG is defined by an elevated FG concentration ( $\geq 100$ and $<126 \mathrm{mg} / \mathrm{dl})$. It is 
well known that IFG and IGT are intermediate states in glucose metabolism. Studies showed that up to $16 \%$ of patients with first-episode drug-naïve schizophrenia have IFG. Secondly, the number of studies for HbA1c and two-hour OGTT levels was small. After excluding one outliner (Qin 2007), the heterogeneity was decreased from $86 \%$ to $30 \%$. Then, we found that the number of patients and controls were not matched in the study. Another limitation was that studies included in our analysis varied in their definition of antipsychotic naive. 5 of 19 studies prescribed that cases could have taken antipsychotics in different period (maximum of 2 weeks). However, the results of FG and two-hour OGTT in these studies were in line with studies in which case are drug naïve. These findings support the assertion that exposure to antipsychotic medication in short term is unlikely to confound the results of this meta-analysis. Additionally, several studies have limited matching data. 5 of 19 studies have not matched with BMI. Several studies also have not matched with lifestyle, such as diet and smoking.

\section{CONCLUSION}

Despite the limitations of our study, our results highlight the glycemic abnormalities in patients with first-episode drug-naïve schizophrenia. Thus, we should heighten the alteration of glycemic indices in patients with first-episode schizophrenia, which is essential to decrease the risk of 2TDM.

\section{Acknowledgements: None.}

\section{Conflict of interest: None to declare.}

\section{Contribution of individual authors:}

Data from eligible studies were extracted by six independent reviewers: Lulu Zheng, Bei Zheng, Shen Zeng, Jingjing Li, Bingqing Liang \& Jun Zhu.

Wenjuan Yang was responsible for the data collection and writing the manuscript.

Meiling Zhang was responsible for statistical analyses and took part in the writing of the manuscript.

All authors took part in reviewing draft versions of the manuscript and approved of the final version.

\section{References}

1. Amare AT, Schubert KO, Klingler-Hoffmann M, CohenWoods S, Baune BT: The genetic overlap between mood disorders and cardiometabolic diseases: a systematic review of genome wide and candidate gene studies. Transl Psychiatry 2017; 7:e1007

2. Arranz B, Rosel P, Ramirez N, Duenas R, Fernandez P, Sanchez JM et al.: Insulin resistance and increased leptin concentrations in noncompliant schizophrenia patients but not in antipsychotic-naive first-episode schizophrenia patients. J Clin Psychiatry 2004; 65:1335-1342
3. Belvederi Murri M, Prestia D, Mondelli V, Pariante C, Patti $S$, Olivieri $B$ et al.: The HPA axis in bipolar disorder: Systematic review and meta-analysis. Psychoneuroendocrinology 2016; 63:327-342

4. Brown S, Kim M, Mitchell C\& Inskip H: Twenty-five year mortality of a community cohort with schizophrenia. Br J Psychiatry 2010; 196:116-121

5. Capasso R, Lineberry T, Bostwick J, Decker P \& St Sauver J: Mortality in schizophrenia and schizoaffective disorder: an Olmsted County, Minnesota cohort: 19502005. Schizophr Res 2008; 98:287-294

6. Charlson FJ, Ferrari AJ, Santomauro DF, Diminic S, Stockings E, Scott JG et al.: Global Epidemiology and Burden of Schizophrenia: Findings From the Global Burden of Disease Study 2016. Schizophr Bull 2018

7. Chen S, Broqueres-You D, Yang G, Wang Z, Li Y, Wang N et al.: Relationship between insulin resistance, dyslipidaemia and positive symptom in Chinese antipsychoticnaive first-episode patients with schizophrenia. Psychiatry Res 2013; 210:825-829

8. Chesney E, Goodwin G \& Fazel S: Risks of all-cause and suicide mortality in mental disorders: a meta-review. World Psychiatry 2014; 13:153-160

9. Chouinard VA, Henderson DC, Dalla Man C, Valeri L, Gray BE, Ryan KP et al: Impaired insulin signaling in unaffected siblings and patients with first-episode psychosis. Mol Psychiatry, 2018

10. Cloutier M, Aigbogun M, Guerin A, Nitulescu R, Ramanakumar A, Kamat $S$ et al.: The Economic Burden of Schizophrenia in the United States in 2013. J Clin Psychiatry 2016; 77:764-771

11. Cohen D \& Correll C: Second-generation antipsychoticassociated diabetes mellitus and diabetic ketoacidosis: mechanisms, predictors, and screening need. J Clin Psychiatry 2009; 70:765-766

12. Crump C, Winkleby M, Sundquist $K \&$ Sundquist J: Comorbidities and mortality in persons with schizophrenia: a Swedish national cohort study. Am J Psychiatry 2013; 170:324-333

13. Dasgupta A, Singh OP, Rout JK., Saha T \& Mandal S: Insulin resistance and metabolic profile in antipsychotic naive schizophrenia patients. Prog Neuropsychopharmacol Biol Psychiatry 2010; 34:1202-1207

14. Enez Darcin A, Yalcin Cavus S, Dilbaz N, Kaya $H$ \& Dogan E: Metabolic syndrome in drug-nä̈ve and drugfree patients with schizophrenia and in their siblings. Schizophrenia Research 2015; 166:201-206

15. Fernandez-Egea E, Bernardo M, Donner T, Conget I, Parellada E, Justicia A, et al.: Metabolic profile of antipsychotic-naive individuals with non-affective psychosis. Br J Psychiatry 2009; 194:434-438

16. Freeman AM \& Pennings $N$ : Insulin Resistance. In StatPearls. StatPearls Publishing StatPearls Publishing LLC.: Treasure Island (FL) 2018

17. Garcia-Rizo C, Kirkpatrick B, Fernandez-Egea E, Oliveira $C$ \& Bernardo M: Abnormal glycemic homeostasis at the onset of serious mental illnesses: A common pathway. Psychoneuroendocrinology 2016; 67:70-75

18. Greenhalgh AM, Gonzalez-Blanco L, Garcia-Rizo C, Fernandez-Egea E, Miller B, Arroyo MB, Kirkpatrick B et al: Meta-analysis of glucose tolerance, insulin, and insulin resistance in antipsychotic-naive patients with nonaffective psychosis. Schizophr Res 2017; 179:57-63 
19. Henderson D, Copeland P, Borba C, Daley T, Nguyen D, Cagliero $E$ et al.: Glucose metabolism in patients with schizophrenia treated with olanzapine or quetiapine: a frequently sampled intravenous glucose tolerance test and minimal model analysis. J Clin Psychiatry 2006; 67:789-797

20. Hjorthøj C, Stürup AE, McGrath J \& Nordentoft M: SA57. Life Expectancy and Years of Potential Life Lost in Schizophrenia: A Systematic Review and Meta-Analysis. Schizophrenia Bulletin 2017; 43:S133-S134

21. Kucukgoncu S, Kosir U, Zhou E, Sullivan E, Srihari VH, Tek C: Glucose metabolism dysregulation at the onset of mental illness is not limited to first episode psychosis: A systematic review and meta-analysis. Early Interv Psychiatry 2019; 13:1021-1031

22. Laursen T: Life expectancy among persons with schizophrenia or bipolar affective disorder. Schizophr Res 2011; 131: 101-104

23. Liu YF, Wang YP, Zhang PF, Yuan XX, Zhu QY, Li X, et al.: Correlation of serum level of homocysteine and insulin resistance with cognitive dysfunction in first $\square$ Natl Med J China 2018; 98:191-195

24. Meyer $J$ \& Stahl S: The metabolic syndrome and schizophrenia. Acta Psychiatr Scand 2009; 119:4-14

25. Moher D, Liberati A, Tetzlaff J \& Altman D: Preferred reporting items for systematic reviews and meta-analyses: the PRISMA statement. PLoS Med 2009; 6:e1000097

26. Perry BI, McIntosh G, Weich S, Singh $S$ \& Rees K: The association between first-episode psychosis and abnormal glycaemic control: systematic review and meta-analysis. Lancet Psychiatry 2016; 3:1049-1058

27. Petrikis P, Tigas S, Tzallas AT, Papadopoulos I, Skapinakis $P \&$ Mavreas $V$ : Parameters of glucose and lipid metabolism at the fasted state in drug-naive firstepisode patients with psychosis: Evidence for insulin resistance. Psychiatry Res 2015; 229:901-904

28. Pillinger T, Beck K, Gobjila C, Donocik J, Jauhar $S$ \& Howes O: Impaired Glucose Homeostasis in First-Episode Schizophrenia: A Systematic Review and Meta-analysis. JAMA Psychiatry 2017; 74:261-269

29. Qin F, Yu JL, Zheng HP, Ma C, Hu WS, Cai YL et al.: Study on early changes of glucose metabolism in firstepisode schizophrenia patients. J South Med Univ 2007; 27:841-842

30. Quan JJ, Lan J, Yang JM: Study on glucose metabolism in first-episode, drug-naive patients with schizophrenia. J Med Postgra 2015; 28:733-736

31. Rajkumar A, Horsdal H, Wimberley T, Cohen D, Mors $O$, Børglum A et al.: Endogenous and Antipsychotic-Related Risks for Diabetes Mellitus in Young People With Schizophrenia: A Danish Population-Based Cohort Study. Am J Psychiatry 2017; 174:686-694

32. Reininghaus U, Dutta R, Dazzan P, Doody G, Fearon P, Lappin $J$ et al.: Mortality in schizophrenia and other psychoses: a 10-year follow-up of the AESOP first-episode cohort. Schizophr Bull 2015; 41:664-73
33. Ryan MCM, Collins $P \&$ Thakore JH: Impaired fasting glucose tolerance in first-episode, drug-naive patients with schizophrenia. The American Journal Of Psychiatry 2003; 160:284-289

34. Saha S, Chant D \& McGrath J: A systematic review of mortality in schizophrenia: is the differential mortality gap worsening over time? Arch Gen Psychiatry 2007; 64:1123-1131

35. Sengupta S, Parrilla-Escobar MA, Klink R, Fathalli F, Ying Kin N, Stip E et al.: Are metabolic indices different between drug-naive first-episode psychosis patients and healthy controls? Schizophr Res 2008; 102:329-336

36. Spelman LM, Walsh PI, Sharifi N, Collins P \& Thakore $J H$ : Impaired glucose tolerance in first-episode drugnaive patients with schizophrenia. Diabet Med 2007; 24:481-485

37. Vancampfort D, Correll C, Galling B, Probst M, De Hert $M$, Ward $P$ et al.: Diabetes mellitus in people with schizophrenia, bipolar disorder and major depressive disorder: a systematic review and large scale meta-analysis. World Psychiatry 2016; 15:166-174

38. Venkatasubramanian $G$ : Antipsychotic-induced weight gain in patients with schizophrenia. Jama 2008; 299: 1899:1899-1900

39. Wan F: Study about glycolipids metabolism profiles in drug-nä̈ve, first-episode schizophrenia patients. Journal of Psychiatry 2015; 28:190-191

40. Wu E, Birnbaum H, Shi L, Ball D, Kessler R, Moulis M et al.: The economic burden of schizophrenia in the United States in 2002. J Clin Psychiatry 2005; 66:1122-9

41. Wu XL, Wei QL, Zhong ZY, Zhao JP, Zheng LR, Li LJ, et al.: The glycometabolism abnormality among schizophrenia patients. Chin J Psychiatry 2012; 45:327-330

42. Wu X, Huang Z, Wu R, Zhong Z, Wei Q, Wang $H$ et al.: The comparison of glycometabolism parameters and lipid profiles between drug-naive, first-episode schizophrenia patients and healthy controls. Schizophr Res 2013; 150:157-62

43. Yood M, DeLorenze G, Quesenberry C, Oliveria $S$, Tsai A, Willey $V$ et al.: The incidence of diabetes in atypical antipsychotic users differs according to agent - results from a multisite epidemiologic study. Pharmacoepidemiol Drug Saf 2009; 18:791-9

44. Yu WJ, Zhu H, Tan LW, Wan F: Metabolism of glucose in first-episode drug-naive patients with schizophrenia and their first-degree relafives. Chin J Behav Med\& Brain Sci 2009; 634-636

45. Zhang XY, Chen DC, Tan YL, An HM, Zunta-Soares GB, Huang XF et al.: Glucose disturbances in first-episode drug-naïve schizophrenia: Relationship to psychopathology. Psychoneuroendocrinology 2015; 62:376-380

46. Zheng $\mathrm{W}$, Li XH, Yang XH, Cai DB, Ungvari GS, $\mathrm{Ng} \mathrm{CH}$ et al.: Adjunctive memantine for schizophrenia: a metaanalysis of randomized, double-blind, placebo-controlled trials. Psychol Med 2018; 48:72-81

Correspondence:

Meiling Zhang, MD

Department of Pharmacy, TongDe Hospital of Zhejiang Province

234 Gucui Rode, Hangzhou, 310 012, China

E-mail: zml9998@sina.com 